\title{
Clinical outcomes in patients co-infected with COVID-19 and Staphylococcus aureus: a scoping review
}

Jenna R. Adalbert ${ }^{1,2^{*}}$, Karan Varshney ${ }^{2,3}$, Rachel Tobin ${ }^{3}$ and Rafael Pajaro ${ }^{4}$

\begin{abstract}
Background: Endemic to the hospital environment, Staphylococcus aureus (S. aureus) is a leading bacterial pathogen that causes deadly infections such as bacteremia and endocarditis. In past viral pandemics, it has been the principal cause of secondary bacterial infections, significantly increasing patient mortality rates. Our world now combats the rapid spread of COVID-19, leading to a pandemic with a death toll greatly surpassing those of many past pandemics. However, the impact of co-infection with S. aureus remains unclear. Therefore, we aimed to perform a high-quality scoping review of the literature to synthesize the existing evidence on the clinical outcomes of COVID-19 and S. aureus co-infection.

Methods: A scoping review of the literature was conducted in PubMed, Scopus, Ovid MEDLINE, CINAHL, ScienceDirect, medRxiv, and the WHO COVID-19 database using a combination of terms. Articles that were in English, included patients infected with both COVID-19 and S. aureus, and provided a description of clinical outcomes for patients were eligible. From these articles, the following data were extracted: type of staphylococcal species, onset of co-infection, patient sex, age, symptoms, hospital interventions, and clinical outcomes. Quality assessments of final studies were also conducted using the Joanna Briggs Institute's critical appraisal tools.

Results: Searches generated a total of 1922 publications, and 28 articles were eligible for the final analysis. Of the 115 co-infected patients, there were a total of 71 deaths (61.7\%) and 41 discharges (35.7\%), with 62 patients (53.9\%) requiring ICU admission. Patients were infected with methicillin-sensitive and methicillin-resistant strains of S. aureus, with the majority (76.5\%) acquiring co-infection with S. aureus following hospital admission for COVID-19. Aside from antibiotics, the most commonly reported hospital interventions were intubation with mechanical ventilation (74.8\%), central venous catheter (19.1\%), and corticosteroids (13.0\%).
\end{abstract}

Conclusions: Given the mortality rates reported thus far for patients co-infected with S. aureus and COVID-19, COVID-19 vaccination and outpatient treatment may be key initiatives for reducing hospital admission and S. aureus co-infection risk. Physician vigilance is recommended during COVID-19 interventions that may increase the risk of bacterial co-infection with pathogens, such as S. aureus, as the medical community's understanding of these infection processes continues to evolve.

Keywords: COVID-19, Staphylococcus aureus, Co-infection, Antibiotics, Hospitalization, Infection

*Correspondence: jenna.adalbert@jefferson.edu

2 Jefferson College of Population Health, 901 Walnut St., Philadelphia, PA 19107, USA

Full list of author information is available at the end of the article

\section{Background}

Upon passage of the March 11th anniversary of the official declaration of the coronavirus disease 2019 (COVID19) pandemic [1], the causative severe acute respiratory 
syndrome coronavirus 2 (SARS-CoV-2) pathogen has infected over 181 million individuals and resulted in more than 3.9 million deaths worldwide as of July 1, 2021 [2]. In addition to rapid spread through high transmission rates [3], infection with COVID-19 can result in severe complications such as acute respiratory distress syndrome (ARDS), thromboembolic events, septic shock, and multi-organ failure [4]. In response to this novel virus, the clinical environment has evolved to accommodate the complexities of healthcare delivery in the pandemic environment [5]. Accordingly, a particularly challenging scenario for clinicians is the management of patients with common infections that may be complicated by subsequent COVID-19 co-infection, or conversely co-infected with a pathogen following primary infection with COVID-19 [6]. Bacterial co-infection in COVID-19 patients may exacerbate the immunocompromised state caused by COVID-19, further worsening clinical prognosis [7].

Implicated as a leading bacterial pathogen in both community- and healthcare-associated infections, Staphylococcus aureus ( $S$. aureus) is commonly feared in the hospital environment for its risk of deadly outcomes such as endocarditis, bacteremia, sepsis, and death [8]. In past viral pandemics, $S$. aureus has been the principal cause of secondary bacterial infections, significantly increasing patient mortality rates [9]. For viral influenza infection specifically, $S$. aureus co-infection and bacteremia has been associated with mortality rates of almost $50 \%$, in contrast to the $1.4 \%$ morality rates observed in patients infected with influenza alone [10]. Given the parallels between the clinical presentation, course, and outcomes of influenza and COVID-19 viral infection [11], mortality rates in COVID-19 patients co-infected with $S$. aureus may reflect those observed in influenza patients. However, while recent studies have focused on the incidence and prevalence of COVID-19 and S. aureus co-infection, the clinical outcomes of patients co-infected with these two specific pathogens remains unclear given that existing studies consolidate $S$. aureus patient outcomes with other bacterial pathogens [12-14].

Given that the literature informing our knowledge of COVID-19 is a dynamic and evolving entity, the purpose of this scoping review is to evaluate the current body of evidence reporting the clinical outcomes of patients coinfected with COVID-19 and S. aureus. To date, there has been no review focusing specifically on the clinical treatment courses and subsequent outcomes of COVID-19 and S. aureus co-infection. In response to the urgency of the pandemic state and high rates of COVID-19 hospital admissions, we aim to identify important areas for further research and explore potential implications for clinical practice.

\section{Methods}

\section{Search strategy and study selection}

To provide a scoping review of initial insight into the breadth of developing data on COVID-19 and S. aureus co-infection, we followed the five-stage methodology of scoping review practice presented by Levac, Colquhoun, and O'Brien [15]. In accordance with the Preferred Reporting Items for Systematic Reviews and Meta-Analyses (PRISMA) extension for Scoping Reviews [16], we conducted electronic searches in PubMed, Scopus, Ovid MEDLINE, CINAHL, ScienceDirect, medRxiv (preprint), and the WHO COVID-19 database between July 3, 2021 and July 16, 2021. Search terms were combined with the use of Boolean operators and included subject headings or key terms specific to COVID-19 (i.e. severe acute respiratory syndrome coronavirus 2 OR SARS-CoV2 OR 2019 novel coronavirus OR 2019-nCoV OR coronavirus disease 2019 virus OR COVID-19 OR Wuhan coronavirus) and Staphylococcus aureus (i.e. methicillin-resistant staphylococcus aureus OR MRSA OR methicillin-susceptible Staphylococcus aureus OR MSSA OR staphylococcal infections). A comprehensive list of our scoping terms and search strategies is included in the Appendix (Ädditional file 1: Table S1). Two independent, experienced reviewers (JA and KV) screened the titles and abstracts of eligible studies and performed full-text review on qualified selections. For this review, we broadly considered articles of any design that included patients infected with both COVID-19 and S. aureus, provided a description of the timeline and ultimate clinical outcomes for these patients (i.e. death or discharge from hospital) at study completion, and were available in English. Studies were excluded if they did not report final outcomes since our scoping review purpose was to evaluate the quality of existing literature that described the clinical course and mortality rate of patients co-infected with these pathogens. We excluded duplicate records and disagreements regarding study inclusion were resolved by consensus or feedback from the senior author.

\section{Data extraction}

For the final articles selected, we completed data extraction in duplicate, and any discrepancies were resolved through discussion or consult with the senior author. While several studies also included reports on patients infected with COVID-19 alone or co-infected with an alternative pathogen, we extracted data solely for patients with COVID-19 and S. aureus co-infection. Our data extraction items included study methodology, author and study location, type of staphylococcal species, onset of $S$. aureus infection, S. aureus culture site and infection source, patient sample size, age, gender, presentation, comorbidities or additional co-infections, prior history 


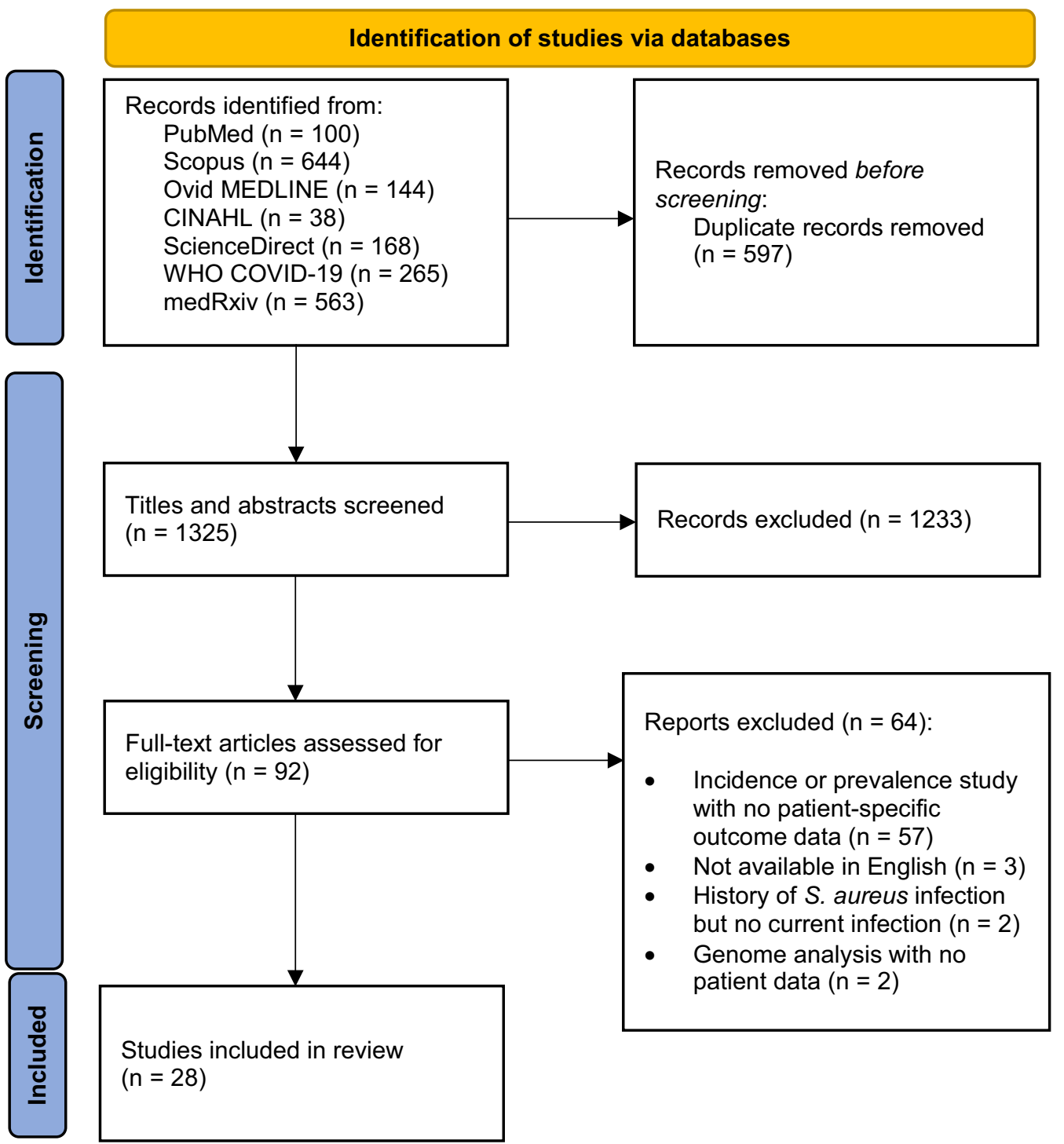

Fig. 1 Process of searching and selecting articlesincluded in the scoping review based on the PRISMA 2020 flow diagram

of $S$. aureus infection, diagnostic findings, hospital treatments and interventions, complications, total length of hospital admission, intensive care unit transfer, and final patient mortality outcomes upon study completion.

\section{Data synthesis and analysis}

Microsoft Excel 2016 (Redmond, WA, USA) was used to collect and chart data extracted from the studies that met the inclusion criteria. Data was synthesized and analyzed descriptively, with frequency counts performed for individual and grouped study metrics. The purpose of synthesizing the extracted information through this method was to create an overview of existing knowledge and identify gaps in the current literature on COVID-19 and $S$. aureus co-infection.

\section{Quality assessment}

Given that the majority of existing literature reporting outcomes data for COVID-19 and S. aureus co-infection were case reports, we utilized the Joanna Briggs Institute's critical appraisal tools [17] to provide a metric for our scoping assessment of the methodological quality of the included studies. Application of these tools enabled examination of study quality in the areas of inclusion criteria, sample size, description of study participants, setting, and the appropriateness of the statistical analysis. 
As in previous reviews $[18,19]$, the tools were modified to produce a numeric score with case reports assessed based on an eight-item scale, case series on a ten-item scale, and cohort studies on an eleven-item scale. Studies were assessed with the methodological quality tool specific to their design (i.e. case report, case series, cohort) by two independent reviewers (JA and KV) and discrepancies were resolved through discussion. While debate exists regarding the minimal number of patients required for study qualification as a "case series" [20], we considered studies reporting individual patient data as "case reports" and those reporting aggregate patient data as "case series." Our complete quality assessment, including tools and scores, is available in the Appendix (Additional file 1: Tables S2-S4).

\section{Results}

Our search strategy produced a total of 1922 potential publications with patients co-infected by COVID-19 and $S$. aureus. For transparent and reproducible methods, the PRISMA 2020 flow diagram for new systematic reviews was utilized to display the search results of our scoping review (Fig. 1). Following deduplication $(\mathrm{n}=597)$ and a comprehensive screen of study titles and abstracts for irrelevant material $(n=1233)$, we reviewed 92 full texts for inclusion eligibility. Of these texts, 64 did not include patient outcomes for COVID-19 and $S$. aureus co-infected patients: 57 were incidence or prevalence studies with no patient-specific outcomes data, two included patients with COVID-19 and a history of $S$. aureus infection but no current COVID-19 and S. aureus co-infection, two were genome analysis studies with no patient data, and three were unavailable in English (Additional file 1: Table S5).

\section{Publication types and geography}

Following full-text review, 28 studies qualified for inclusion in our review, resulting in a total of 115 patients. Of these 28 included studies, 22 were case reports (describing single patients with individual data), two were case series (describing 7-42 patients with aggregate data), and four were cohort studies (describing 4-40 patients with aggregate data). Countries of study publication included the United States $(\mathrm{n}=7)[7,9$, 21-25], Italy $(n=7)$ [26-32], Japan $(n=2)$ [33, 34], Iran $(\mathrm{n}=2)[35,36]$, the United Kingdom $(\mathrm{n}=2)[37$, 38], Spain $(n=2)[39,40]$, Bahrain $(n=1)$ [41], China $(n=1)$ [42], France $(n=1)$ [43], the Philippines $(n=1)$ [44], Korea $(n=1)$ [45], and Canada $(n=1)$ [46], with publication dates ranging from April 15, 2020 to June 16,2021 . Table 1 describes the characteristics of these included studies and available information on their respective patient demographics in detail.

\section{Publication quality}

Figure 2 represents the quality assessment scores produced by the Joanna Briggs Institute's critical appraisal tools. Scores ranged from 2 to 8 for case reports (out of 8 points total) $(n=22), 6-9$ for case series (out of 10 points total) $(\mathrm{n}=2)$, and $6-8$ for cohort studies (out of 11 points total) $(\mathrm{n}=4)$. The mean quality assessment score for these publications compared within their respective categories was 6.8 for case reports, 7.5 for case series, and 7.3 for cohort studies. In terms of most common study design limitations, the metric of patient post-intervention clinical conditions was least clearly described for case reports, neither of the case series consecutively included participants, and strategies to address incomplete followup were only reported for one of the four cohort studies.

\section{Patient demographics}

For the 115 total patients included in our review that were co-infected with COVID-19 and S. aureus, their demographic (Table 1) and clinical data (Table 2) were described with varying completeness. Staphylococcal species and patient outcomes are reported in both tables to enable direct comparison with patient demographics and clinical course. Across our patient sample, the mean patient age was 54.8 years $(\mathrm{SD}=21.6)$, $65.3 \%(n=75)$ were male, $32.1 \%(n=37)$ were female, and 3 patients $(2.6 \%)$ did not have their gender specified in the study. Patients presented with a diversity of comorbidities with diabetes mellitus $(33.9 \%, \mathrm{n}=39)$, hypertension $(32.2 \%, \mathrm{n}=37)$, and cardiovascular disease $(28.7 \%, \mathrm{n}=33)$ reported as the most common. Five patients presented with no comorbidities and four studies reported no information on patient medical history related to comorbidities. The most common presenting symptoms reported by patients at hospital admission included cough $(13.9 \%, \mathrm{n}=16)$, fever $(13.9 \%, \mathrm{n}=16)$, and dyspnea $(13.0 \%, \mathrm{n}=15)$.

\section{Infection characteristics}

In terms of specific staphylococcal species co-infection, $51.3 \%(\mathrm{n}=59)$ of patients were infected with methicillin-sensitive staphylococcus aureus (MSSA) and $49.6 \%(\mathrm{n}=57)$ were infected with methicillinresistant staphylococcus aureus (MRSA), with a single patient co-infected with both MRSA and MSSA. One patient co-infected with MSSA had a fatal Panton-Valentine Leukocidin toxin-producing strain of MSSA (PVL-MSSA). In addition to COVID-19 and S. aureus co-infection, $26.1 \%(\mathrm{n}=30)$ of patients were co-infected with one or more separate pathogens such as Klebsiella pneumoniae $(\mathrm{n}=6)$, Candida spp. $(\mathrm{n}=6)$, Enterococcus spp. $(\mathrm{n}=5)$, Haemophilus 


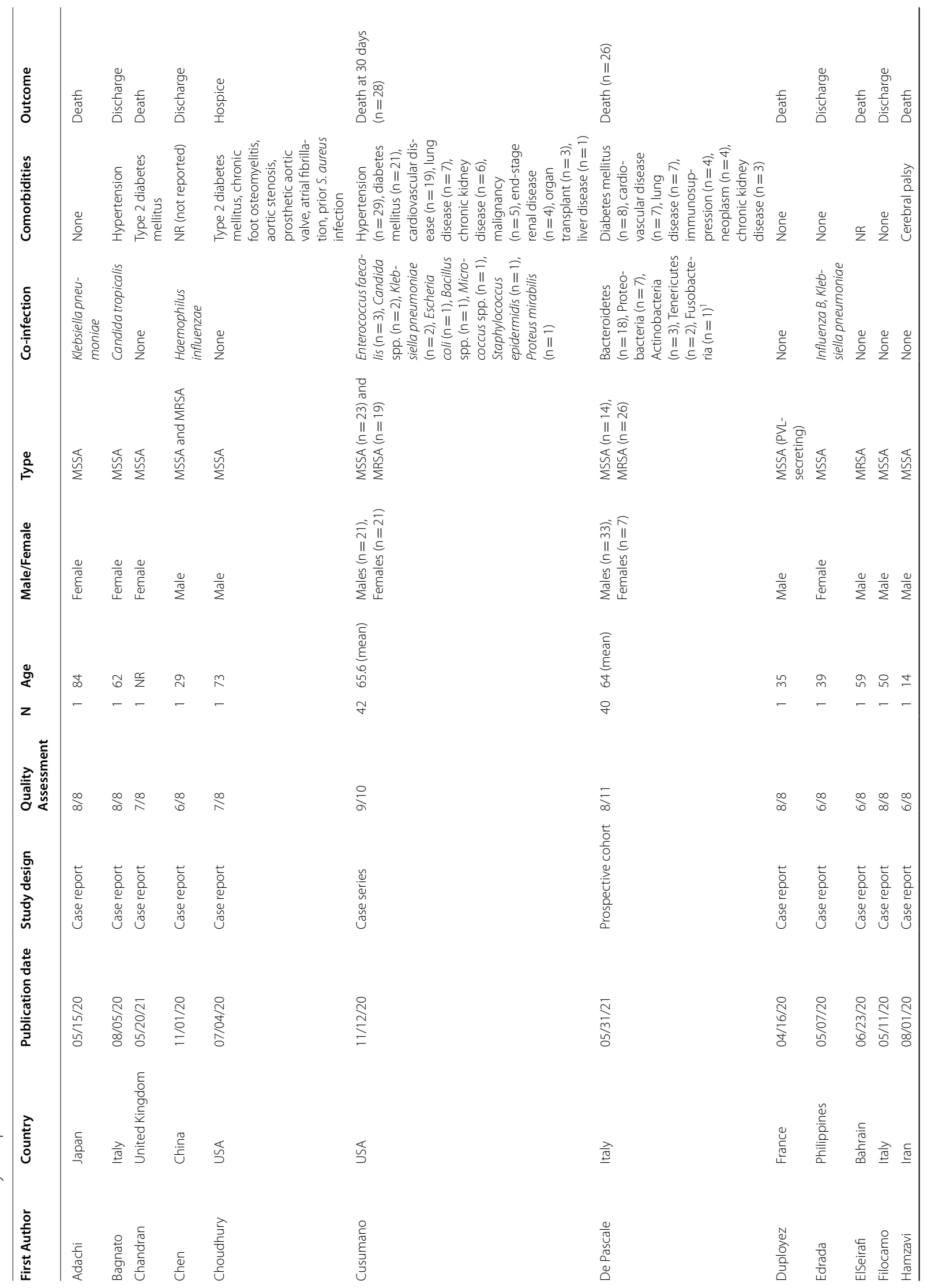




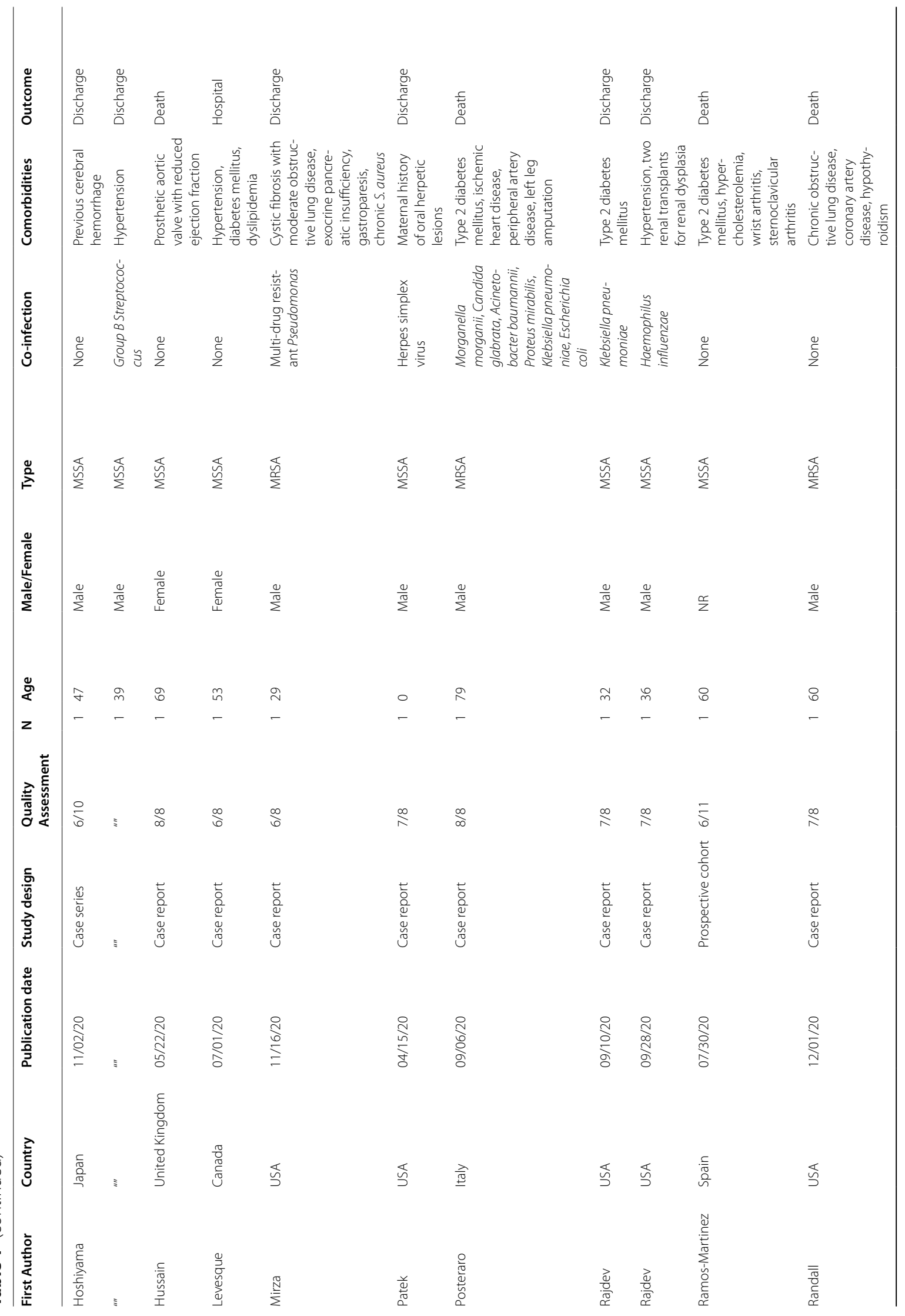




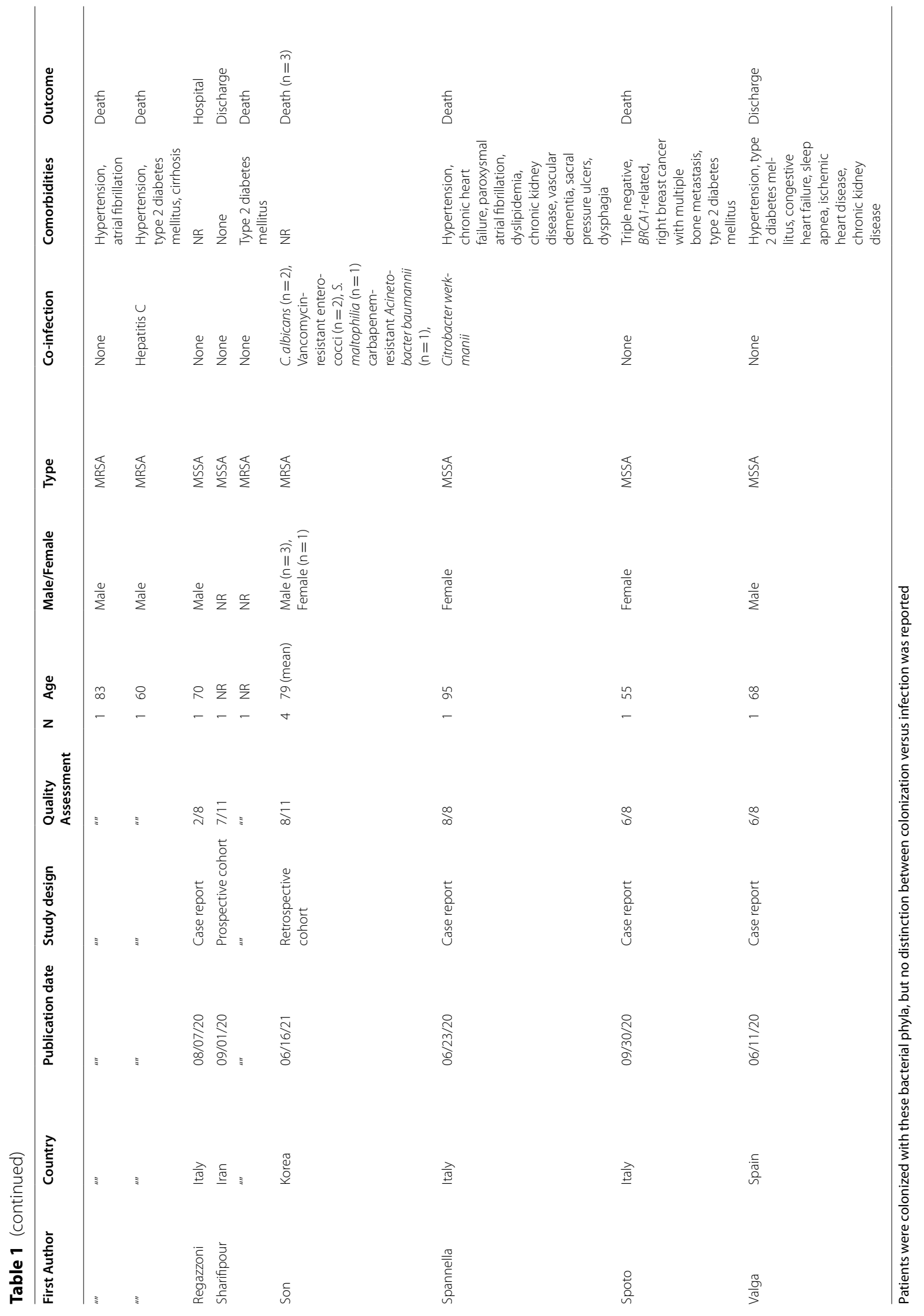




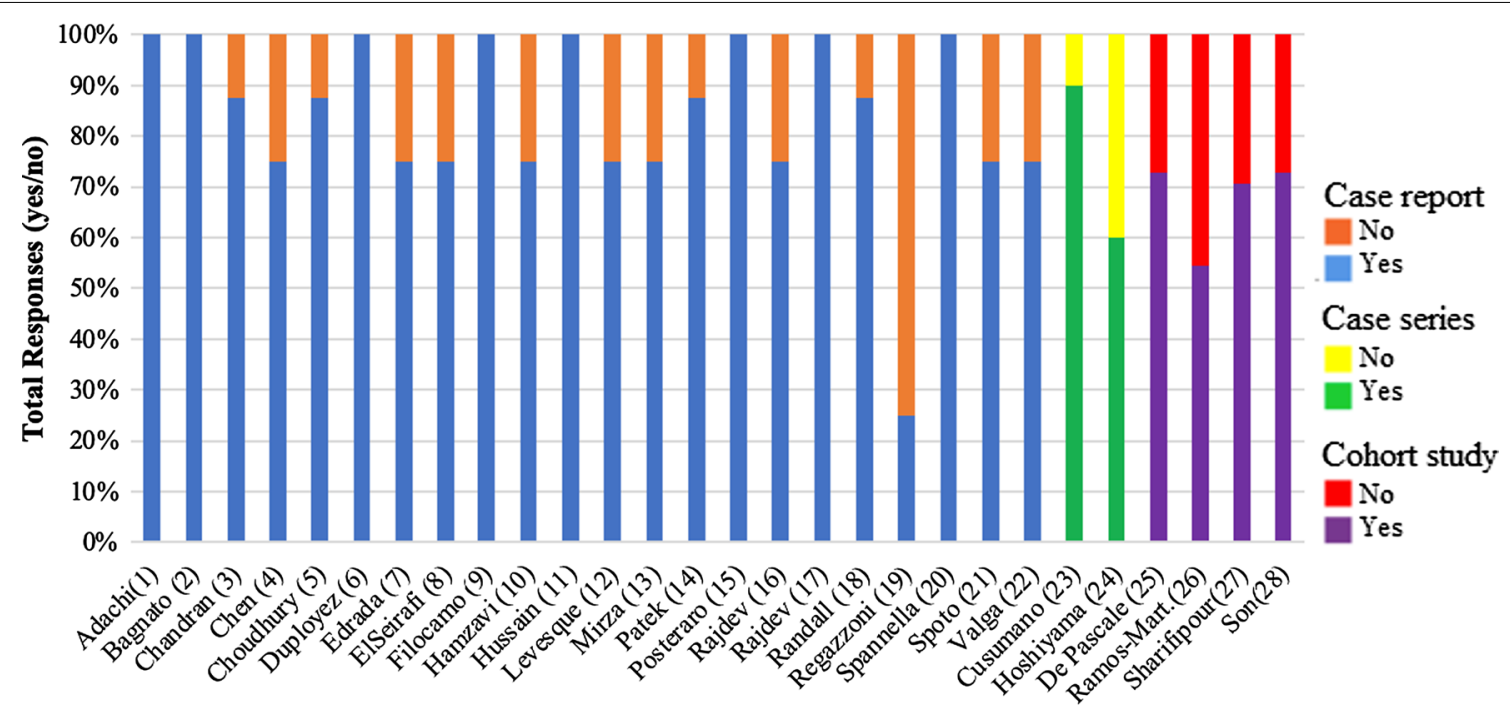

Publication

Fig. 2 Quality assessment scores for includedpublications reported as "yes" or "no" for achieving quality metrics per theJoanna Briggs Institute's critical appraisal tools

influenzae $(\mathrm{n}=2)$, Proteus mirabilis $(\mathrm{n}=2)$, Escherichia coli $(\mathrm{n}=2)$. Comprehensive patient co-infection data are reported in Table 1.

\section{Diagnoses and treatments}

Of all 115 reported cases of co-infection with COVID19 and $S$. aureus, diagnosis of S. aureus infection was most frequently established by blood culture in our patient sample $(64.3 \%, \mathrm{n}=74)$, with $S$. aureus infections manifesting predominantly in patients as bacteremia $(64.3 \%, \mathrm{n}=74)$ and pneumonia $(55.7 \%, \mathrm{n}=64)$, accompanied by several additional endocarditis/vasculitis $(3.5 \%, \mathrm{n}=4)$, cellulitis $(1.7 \%, \mathrm{n}=2)$, and osteomyelitis $(0.9 \%, \mathrm{n}=1)$ cases. Additionally, two patients that tested positive for $S$. aureus with no clear infection source were suspected to be chronic carriers of the bacterial pathogen. From this variety of infection presentations, the majority $(76.5 \%, \mathrm{n}=88)$ experienced hospital-onset $S$. aureus co-infection following hospitalization for an initial infection with COVID19 , and 19 patients (16.5\%) presented with S. aureus infection at the time of admission that was determined to be community-onset in etiology. Aside from a standard course of antibiotics, patients received a diversity of adjuvant treatments during their hospital admission, with the most common interventions including intubation and mechanical ventilation $(74.8 \%, \mathrm{n}=86)$, a central venous catheter $(19.1 \%$, $\mathrm{n}=22)$, and corticosteroids $(13.0 \%, \mathrm{n}=15)$. Table 2 describes the clinical course following hospital admission for each patient in comprehensive detail.

\section{Complications and outcomes}

During the hospital course of the 115 co-infected patients in our review, the most common complications were sepsis or systemic inflammatory response syndrome $(23.5 \%, \mathrm{n}=27)$, acute kidney injury $(5.2 \%$, $\mathrm{n}=6)$, acute respiratory distress syndrome $(4.3 \%$, $\mathrm{n}=5)$, pneumonia $(4.3 \%, \mathrm{n}=5)$, and multi-organ dysfunction or failure $(4.3 \%, n=5)$. Transfer to an intensive care unit during admission was clearly reported for $53.9 \%(n=62)$ of patients, unnecessary for $4.3 \%$ $(n=5)$, and not reported for the remaining $41.8 \%$ $(\mathrm{n}=48)$. Patients were admitted for a mean length of 26.2 days $(\mathrm{SD}=26.7)$ to any type of inpatient hospital unit, with the length of hospital stay not reported in five cases. Upon analysis of the final outcomes reported for the hospital course of our co-infected COVID-19 and S. aureus patient sample, 71 (61.7\%) patients died, $41(35.7 \%)$ were discharged, two remained hospitalized and in stable condition on study conclusion, and one patient was placed in hospice care. Table 2 further details the specific complications presenting in each patient's hospital trajectory and Table 3 reports the final pooled frequencies of patient co-infection characteristics and outcomes.

\section{Discussion}

As our evidence base of the outcomes of patients with COVID-19 infection continues to expand, thorough review of the various clinical scenarios and environments inherent to the treatment process of this disease are crucial for patient care management and improvement. 


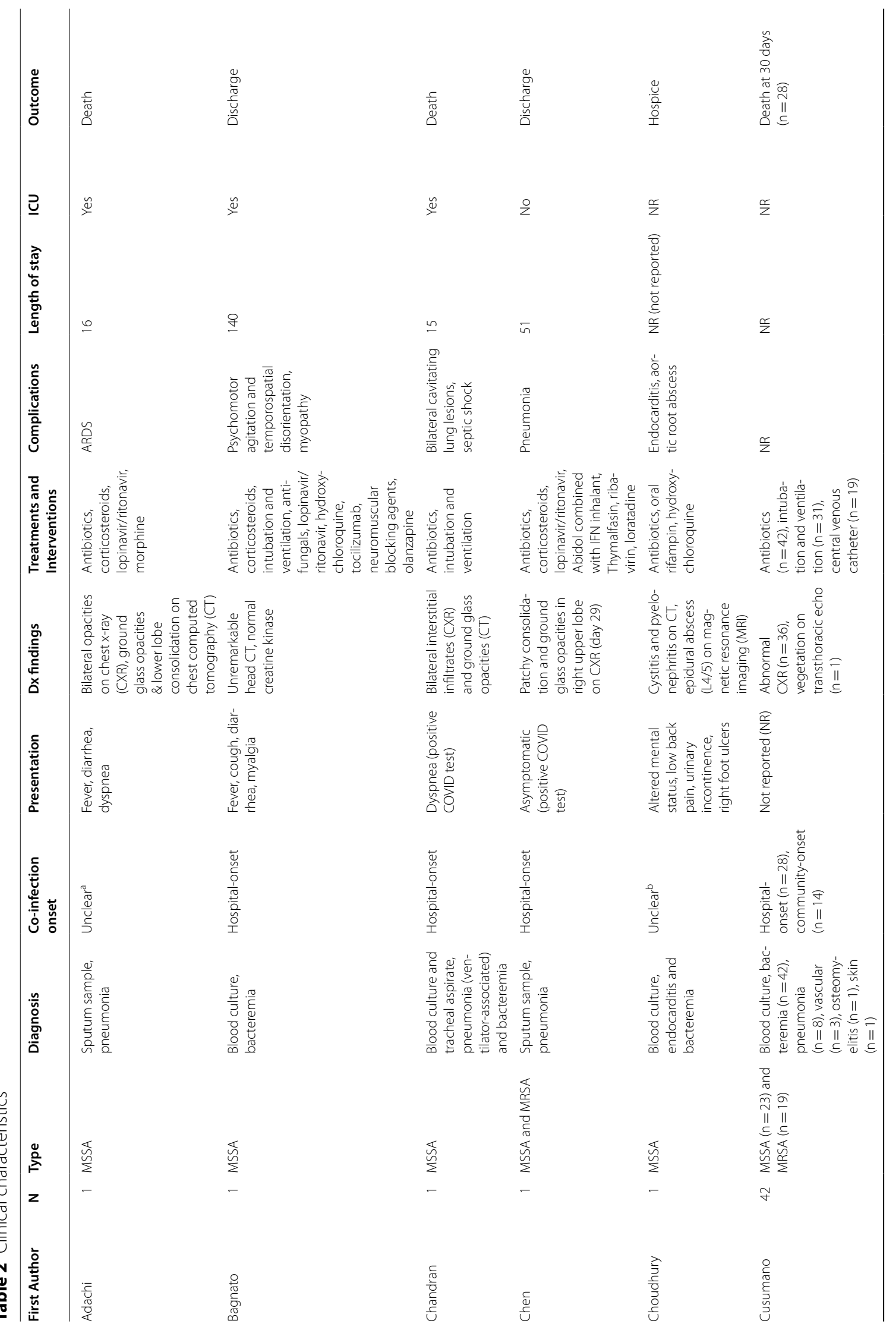




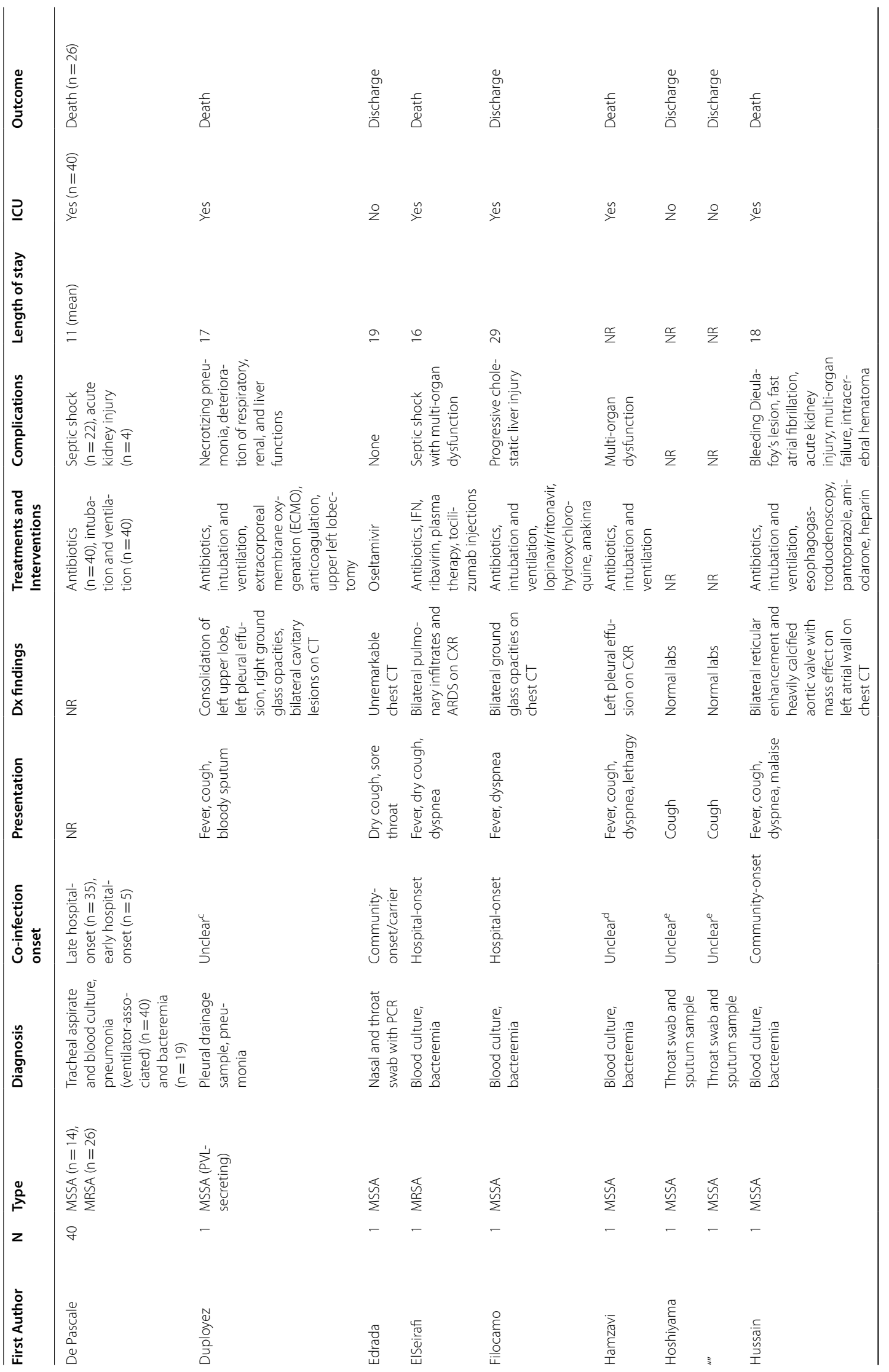




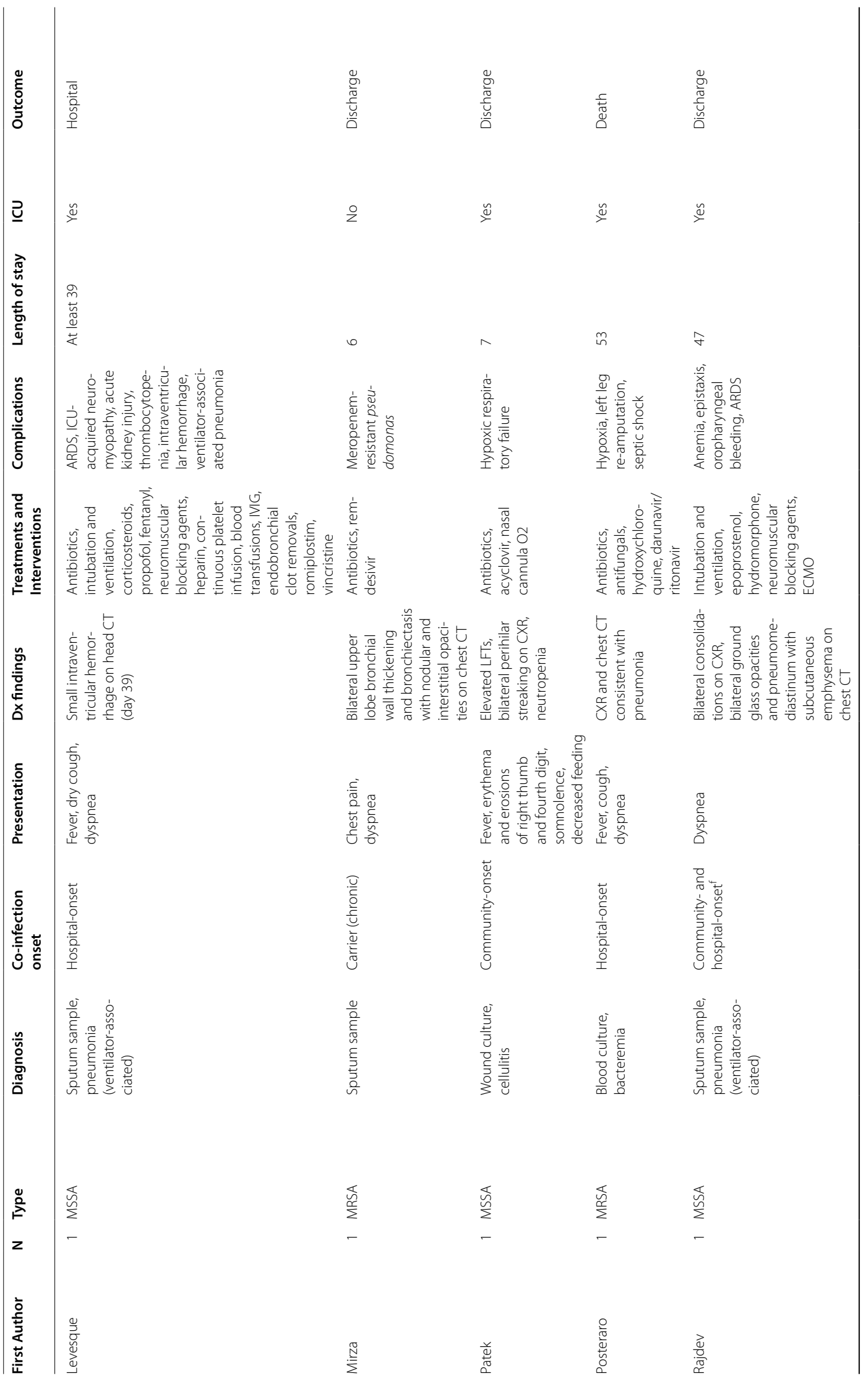




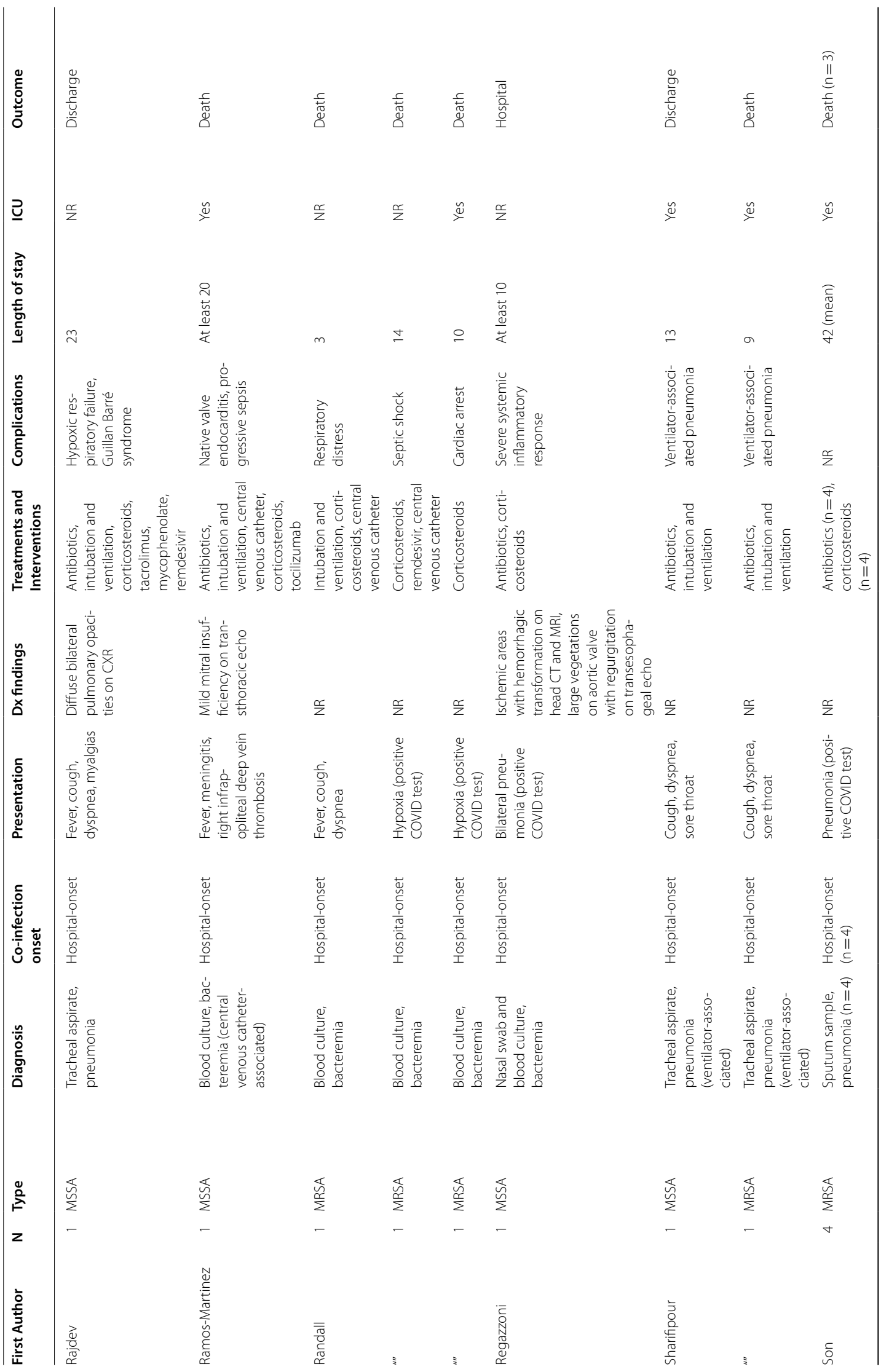




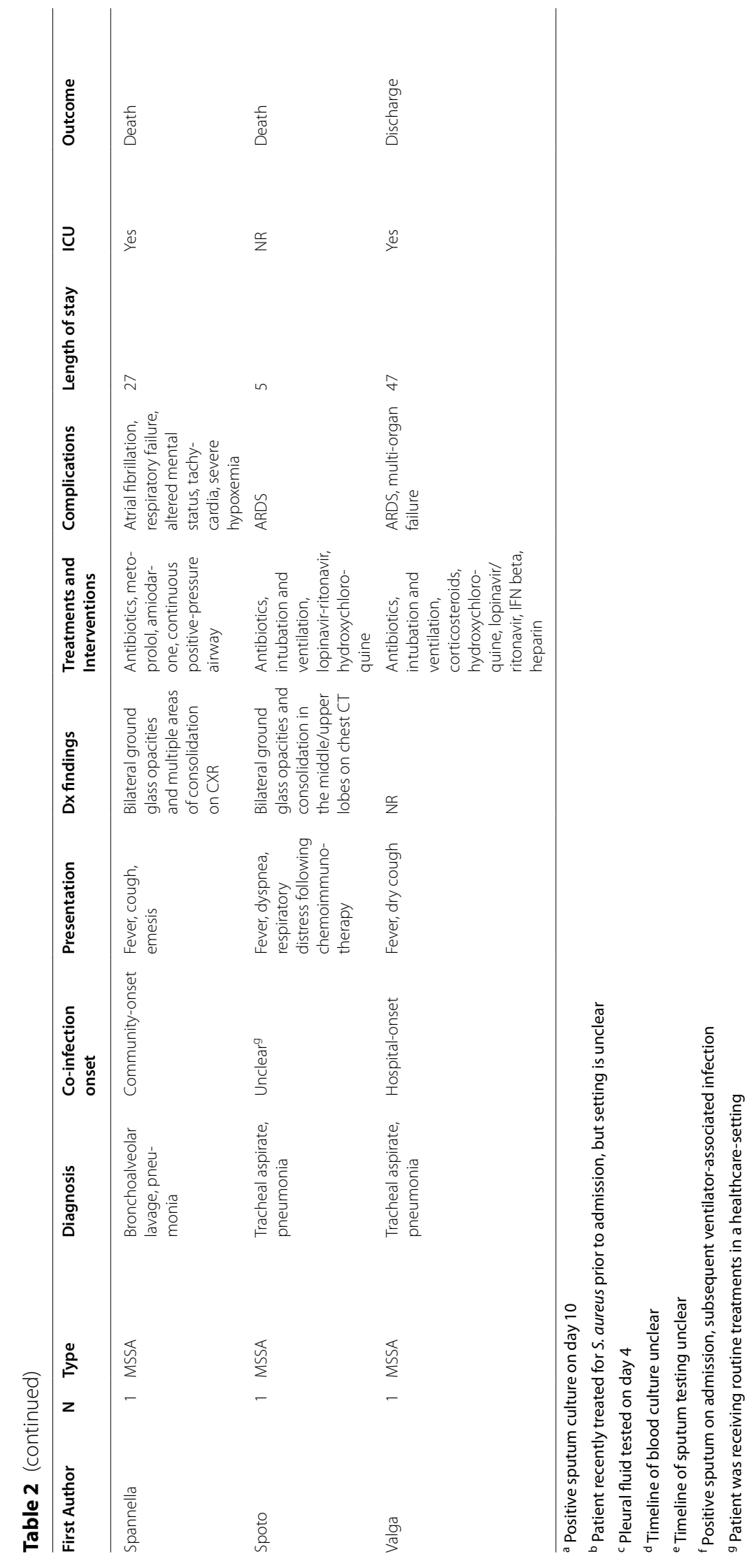


Table 3 Pooled frequencies of patient co-infection characteristics and outcomes $(n=115)$

\begin{tabular}{|c|c|}
\hline & Total (\%) \\
\hline \multicolumn{2}{|l|}{ Gender } \\
\hline Male & $75(65.3)$ \\
\hline Female & $37(32.1)$ \\
\hline Unspecified & $3(2.6)$ \\
\hline \multicolumn{2}{|l|}{ Staphylococcal Species } \\
\hline MSSA & $59(51.3)$ \\
\hline MRSA & $57(49.6)$ \\
\hline \multicolumn{2}{|l|}{ Co-infection } \\
\hline Klebsiella pneumoniae & $6(5.2)$ \\
\hline Candida spp. & $6(5.2)$ \\
\hline Enterococcus spp. & $5(4.3)$ \\
\hline Hemophilus influenzae & $2(1.7)$ \\
\hline Escherichia coli & $2(1.7)$ \\
\hline Proteus mirabilis & $2(1.7)$ \\
\hline Acinetobacter baumannii & $2(1.7)$ \\
\hline Bacillus spp. & $1(0.9)$ \\
\hline Staphylococcus epidermidis & $1(0.9)$ \\
\hline Micrococcus spp. & $1(0.9)$ \\
\hline Pseudomonas spp. & $1(0.9)$ \\
\hline Morganella morganii & $1(0.9)$ \\
\hline Citrobacterwerkmanii & $1(0.9)$ \\
\hline S. maltophilia & $1(0.9)$ \\
\hline Hepatitis C & $1(0.9)$ \\
\hline Herpes simplex virus & $1(0.9)$ \\
\hline Group B Streptococcus & $1(0.9)$ \\
\hline None & $83(72.2)$ \\
\hline \multicolumn{2}{|l|}{ S. Aureus Diagnostic Test } \\
\hline Blood culture & $74(64.3)$ \\
\hline Tracheal aspirate & $46(40.0)$ \\
\hline Sputum sample & $11(9.5)$ \\
\hline Nasal swab & $2(1.7)$ \\
\hline Lower respiratory tract sample & $2(1.7)$ \\
\hline Chronic carrier & $2(1.7)$ \\
\hline Wound culture & $1(0.9)$ \\
\hline \multicolumn{2}{|l|}{ S. aureus Diagnosis } \\
\hline Bacteremia & $74(63.4)$ \\
\hline Pneumonia & $64(55.7)$ \\
\hline Ventilator-associated & $44(38.3)$ \\
\hline Endocarditis/vasculitis & $4(3.5)$ \\
\hline Cellulitis & $2(1.7)$ \\
\hline Chronic carrier & $2(1.7)$ \\
\hline Osteomyelitis & $1(0.9)$ \\
\hline Not reported & $2(1.7)$ \\
\hline \multicolumn{2}{|l|}{ S. AureusInfection Onset } \\
\hline Hospital & $88(76.5)$ \\
\hline Community & $19(16.5)$ \\
\hline Unclear & $7(6.1)$ \\
\hline \multicolumn{2}{|l|}{ Complications } \\
\hline Sepsis/Systemic Inflammatory Response Syndrome & $27(23.5)$ \\
\hline
\end{tabular}

Table 3 (continued)

\begin{tabular}{lc}
\hline & Total (\%) \\
\hline Acute kidney injury & $6(5.2$ \\
Acute respiratory distress syndrome & $5(4.3)$ \\
Pneumonia & $5(4.3)$ \\
Multi-organ dysfunction/failure & $5(4.3)$ \\
Bleeding/coagulopathy & $5(4.3)$ \\
Hypoxic respiratory failure & $3(2.6)$ \\
Myopathy/neuropathy & $3(2.6)$ \\
Abscess formation & $2(1.7)$ \\
Confusion and altered mental status & $2(1.7)$ \\
Atrial fibrillation & $2(1.7)$ \\
Endocarditis & $2(1.7)$ \\
Anemia & $1(0.9)$ \\
Cardiac arrest & $1(0.9)$ \\
Thrombocytopenia & $1(0.9)$ \\
Re-amputation & $1(0.9)$ \\
Cholestatic liver injury & $1(0.9)$ \\
Not reported & $3(2.6)$ \\
ICU & \\
Yes & $62(53.9)$ \\
No & $5(4.3)$ \\
Not reported & $48(41.8)$ \\
Outcome & \\
Death & $71(61.7)$ \\
Discharge & $41(35.7)$ \\
Hospital & $2(1.7)$ \\
Hospice & $1(0.9)$ \\
& \\
\hline
\end{tabular}

Given that higher levels of morbidity and death have been observed in influenza patients co-infected with multiple pathogens during past pandemics [47], exploring the outcomes of co-infected COVID-19 patients may establish similar trends and reveal strategies for decreasing the morbidity and mortality of this population in our current pandemic. Our review of the available clinical data reporting the outcomes of patients co-infected with COVID-19 and the common bacterial pathogen, $S$. aureus, was purposed to augment this knowledge base and has produced several key findings regarding mortality rate, co-infection onset, and treatment considerations for these patients.

Foremost, the mortality rate in our review for patients co-infected with COVID-19 and S. aureus was $61.7 \%$, which depicts a significantly increased mortality rate when contrasted with patients infected solely by COVID-19 [48]. This outcome is comparable to the increased morality rates observed in patients acquiring co-infection with $S$. aureus in addition to influenza [10], however, our findings emphasize an important difference in the etiology of COVID-19 and influenza 
co-infection with S. aureus. For influenza specifically, co-infection with $S$. aureus is predominantly diagnosed upon patient presentation to a healthcare setting, indicating that the community is a frequent and supportive environment for the co-infection processes of these pathogens $[9,49]$. In contrast, our findings indicate that co-infection with $S$. aureus predominantly occurs in the hospital environment for patients with COVID-19 infection. The terminology used to differentiate these infection etiologies is "communityassociated" versus "healthcare-associated," with delineation between these diagnoses occurring at 48-hours after admission to a hospital or healthcare facility [50]. Given that co-infection with COVID-19 and S. aureus occurred after hospital admission in $76.5 \%$ of the patients in our review, preventative measures in the community-setting or treatment in an outpatient environment may be important considerations for mortality reduction from healthcare-associated $S$. aureus infection.

Importantly, while the predominance of $S$. aureus coinfections occurring after patient admission for COVID19 infection is likely associated with a wide diversity of patient- and environment-specific factors, our findings suggest that this infection sequence may be partly attributed to the COVID-19 treatment course. The most common patient interventions identified in our review included intubation and mechanical ventilation, central venous catheter placement, and corticosteroids, which are each associated with increased risks of bacterial infection through introduction of a foreign body or immunosuppressive properties that dually support bacterial growth [51, 52]. Although these first-line treatments for decompensating patients that present with severe COVID-19 infection may predispose patients to $S$. aureus bacterial co-infection and subsequently increased mortality rates, they are often unavoidable during the patient treatment course. Vigilant management surrounding these interventions in patients with COVID-19 infection, such as timely central line or ventilator removal and prudent steroid dosing, are key quality improvement practices that warrant routine physician adherence during patient treatment processes given co-infection mortality rates.

In contrast to COVID-19 infection alone, the increased patient morbidity and mortality of COVID-19 and healthcare-associated $S$. aureus co-infection identified in our review have important implications for future research and clinical practice. While of clear and crucial public health importance, our findings further emphasize the imperative of COVID-19 vaccination to reduce both infection and symptom severity that may predispose patients to the necessity of hospital interventions and subsequent $S$. aureus co-infection. The effectiveness of this strategy is exemplified by the reduction in influenza and $S$. aureus pathology observed with increased influenza vaccination $[53,54]$. As seen with influenza coinfection, vaccination may be a crucial harm reduction measure given that no $S$. aureus prophylaxis exists, and the incidence of $S$. aureus strains refractory to antibiotics is rising [55]. Additionally, the mortality trends observed in COVID-19 patients co-infected with S. aureus highlight the necessity for future reviews and clinical studies focused on the co-infection outcomes of other bacterial and viral pathogens alongside COVID-19. Further research may inform our ability to predict the trajectory of patients with various co-infections and identify infection patterns that influence treatment decisions.

To our knowledge, this is the first study to review and evaluate the outcomes of patients co-infected with COVID-19 and S. aureus. However, we acknowledge several limitations to this review. First, the majority of the studies included in our review were individual case reports due to the recent emergence of COVID-19 and limited literature exploring outcomes for patients coinfected with $S$. aureus. While these types of studies can be vital for expanding the medical knowledge base and reveal fundamental disease characteristics, it is crucial to consider the reporting bias that may exist in this study design and lack of comparison groups. Per our quality assessment, trends in study limitations for each type of publication were variable. Accordingly, our intent for this review was to pool these outcomes in order to reduce this bias and transparently report each case for appropriate assessment and application of our findings. In addition, Cusumano et al.s [9] case series comprised 42 of the patients in our review and used a study end-point of death at 30 days, implicating that the true mortality rate of patients with COVID-19 and S. aureus co-infection may be higher if related complications necessitate an extended hospital course. Future high-quality clinical studies examining patient outcomes are warranted and of critical importance to further expand on the findings of our systematic review.

\section{Conclusion}

In contrast to patients infected solely with COVID19, co-infection with COVID-19 and S. aureus demonstrates a higher patient mortality rate during hospital admission. S. aureus co-infection in COVID19 patients is predominantly healthcare-associated, and common hospital interventions for patients with severe COVID-19 infection may increase the risk for bacterial infection. Our findings emphasize the imperative of COVID-19 vaccination to prevent hospitalization for 
COVID-19 treatment and the subsequent susceptibility to hospital-acquired S. aureus co-infection.

\begin{abstract}
Abbreviations
COVID-19: Coronavirus disease 2019; SARS-CoV-2: Severe acute respiratory syndrome coronavirus 2; ARDS: Acute respiratory distress syndrome; S. aureus: Staphylococcus aureus; PRISMA: Preferred Reporting Items for Systematic Reviews and Meta-Analyses; SD: Standard deviation; MSSA: Methicillin-sensitive Staphylococcus aureus; MRSA: Methicillin-resistant Staphylococcus aureus; PVL-MSSA: Panton-Valentine Leukocidin methicillin-sensitive Staphylococcus aureus; NR: Not reported; Dx findings: Diagnostic findings; CXR: Chest x-ray; ICU: Intensive care unit; PCR: Polymerase chain reaction; CT: Computed tomography; LFTs: Liver function tests; ECMO: Extracorporeal membrane oxygenation; IFN: Interferon; MRI: Magnetic resonance imaging.
\end{abstract}

\section{Supplementary Information}

The online version contains supplementary material available at https://doi. org/10.1186/s12879-021-06616-4.

Additional file 1: Table S1. Search strategies, conducted between July 3, 2021, and July 16, 2021. Total results $=1922$. Table S2. Joanna Briggs Quality Assessment for case reports included in the review. Table S3: Joanna Briggs Quality Assessment for case-series included in the review. Table S4. Joanna Briggs Quality Assessment for cohort studies included in the review. Table S5. Excluded articles after full-text analysis, with reason $(n=64)$.

\section{Acknowledgements}

The authors would like to thank the staff of the Thomas Jefferson University Scott Memorial Library for their assistance with search term construction and instruction on optimal review practices.

\section{Authors' contributions}

JA reviewed the articles, as per the PRISMA guidelines, and wrote the majority of the manuscript. KV served as a second reviewer, helped write the abstract, and provided input for final drafts of the manuscript. RT helped to write the Results section of the manuscript. RP analyzed and interpreted data while providing his clinical expertise for relevant edits. All authors read and approved the final manuscript.

\section{Authors' information}

JA is an MD/MPH candidate at Sidney Kimmel Medical College of Thomas Jefferson University, Philadelphia, Pennsylvania, USA. Her research interests include infectious disease epidemiology, the United States opioid epidemic, and improving access to surgical care in low- and middle-income countries

\section{Funding}

No funding was provided to any authors of this study.

\section{Availability of data and materials}

All data generated or analyzed during this study are included in this published article [and its Additional file 1].

\section{Declarations}

\section{Ethics approval and consent to participate}

Not applicable.

\section{Consent for publication}

Not applicable.

\section{Competing interests}

The authors declare that they have no competing interests.

\section{Author details}

1'Sidney Kimmel Medical College at Thomas Jefferson University, Philadelphia, PA, USA. ${ }^{2}$ Jefferson College of Population Health, 901 Walnut St., Philadelphia, PA 19107, USA. ${ }^{3}$ Deakin University School of Medicine, Geelong, Victoria, Australia. ${ }^{4}$ Morristown Medical Center of Atlantic Health System, Morristown, New Jersey, USA.

Received: 1 June 2021 Accepted: 10 August 2021

Published online: 21 September 2021

\section{References}

1. The World Health Organization. WHO Director General's opening remarks at the media briefing on COVID-19. 2020. https://www.who.int/direc tor-general/speeches/detail/who-director-general-s-opening-remarks-atthe-media-briefing-on-covid-19---11-march-2020. Accessed 17 Mar 2021.

2. The World Health Organization. WHO Coronavirus (COVID-19) Dashboard. 2021. https://covid19.who.int/. Accessed 1 July 2021.

3. Cascella M, Rajnik M, Aleem A, Dulebohn SC, Di Napoli R, Features. In: StatPearls, editor. Evaluation, and treatment of coronavirus (COVID-19). Treasure Island (FL): StatPearls Publishing; 2021.

4. Richardson S, Hirsch JS, Narasimhan M, et al. Presenting characteristics, comorbidities, and outcomes among 5700 patients hospitalized with COVID-19 in the New York city area. JAMA. 2020;323(20):2052-9. https:// doi.org/10.1001/jama.2020.6775.

5. Lee TH. Creating the new normal: the clinician response to COVID-19. N Engl J Med Catalyst. 2020. https://doi.org/10.1056/CAT.20.0076.

6. Lai C-C, Wang C-Y, Hsueh P-R. Co-infections among patients with COVID19: the need for combination therapy with non-anti-SARS-CoV-2 agents? J Microbiol Immunol Infect. 2020;53(4):505-12. https://doi.org/10.1016/j. jmii.2020.05.013.

7. Choudhury I, Han H, Manthani K, Gandhi S, Dabhi R. COVID-19 as a possible cause of functional exhaustion of CD4 and CD8 T-cells and persistent cause of methicillin-sensitive Staphylococcus aureus bacteremia. Cureus. 2020;12(7):e9000. https://doi.org/10.7759/cureus.9000.

8. Kourtis AP, Hatfield K, Baggs J, et al. Vital signs: epidemiology and recent trends in methicillin-resistant and in methicillin-susceptible Staphylococcus aureus bloodstream infections - United States. MMWR Morb Mortal Wkly Rep. 2019;68(9):214-9. https://doi.org/10.15585/mmwr.mm6809e1.

9. Cusumano JA, Dupper AC, Malik Y, et al. Staphylococcus aureus bacteremia in patients infected with COVID-19: a case series. Open Forum Infect Dis. 2020;7(11):ofaa518. https://doi.org/10.1093/ofid/ofaa518.

10. Leung $\mathrm{C}-\mathrm{H}$, Tseng H-K, Wang W-S, Chiang H-T, Wu AY-J, Liu C-P. Clinical characteristics of children and adults hospitalized for influenza virus infection. J Microbiol Immunol Infect. 2014;47(6):518-25. https://doi.org/ 10.1016/j.jmii.2013.06.002.

11. Khorramdelazad $H$, Kazemi MH, Najafi A, Keykhaee M, Zolfaghari Emameh R, Falak R. Immunopathological similarities between COVID-19 and influenza: investigating the consequences of Co-infection. Microb Pathog. 2021;152:104554. https://doi.org/10.1016/j.micpath.2020.104554.

12. Adler $H$, Ball R, Fisher M, Mortimer K, Vardhan MS. Low rate of bacterial co-infection in patients with COVID-19. Lancet Microbe. 2020;1(2):e62. https://doi.org/10.1016/S2666-5247(20)30036-7.

13. Adeiza SS, Shuaibu AB, Shuaibu GM. Random effects meta-analysis of COVID-19/S. aureus partnership in co-infection. GMS Hyg Infect Control. 2020;15:Doc29. https://doi.org/10.3205/dgkh000364.

14. Musuuza JS, Watson L, Parmasad V, Putman-Buehler N, Christensen L, Safdar N. Prevalence and outcomes of co-infection and superinfection with SARS-CoV-2 and other pathogens: a systematic review and metaanalysis. PLoS One. 2021;16(5):e0251170. https://doi.org/10.1371/journal. pone.0251170

15. Levac D, Colquhoun $\mathrm{H}, \mathrm{O}^{\prime}$ Brien KK. Scoping studies: advancing the methodology. Implement Sci. 2010;5:69. https://doi.org/10.1186/ 1748-5908-5-69

16. Tricco AC, Lillie E, Zarin W, et al. PRISMA Extension for Scoping Reviews (PRISMA-SCR): checklist and explanation. Ann Intern Med. 2018;169(7):467-73. https://doi.org/10.7326/M18-0850.

17. Joanna Briggs Institute. Critical appraisal tools. 2020. https://jbi.global/ critical-appraisal-tools. Accessed 24 April 2021. 
18. Bowring AL, Veronese V, Doyle JS, Stoove M, Hellard M. HIV and sexual risk among men who have sex with men and women in Asia: a systematic review and meta-analysis. AIDS Behav. 2016;20(10):2243-65. https://doi. org/10.1007/s10461-015-1281-X.

19. Xu Y, Chen X, Wang K. Global prevalence of hypertension among people living with HIV: a systematic review and meta-analysis. J Am Soc Hypertens. 2017;11(8):530-40. https://doi.org/10.1016/j.jash.2017.06.004.

20. Abu-Zidan FM, Abbas AK, Hefny AF. Clinical "case series": a concept analysis. Afr Health Sci. 2012;12(4):557-562. https://doi.org/10.4314/ahs.v12i4. 25

21. Mirza AA, Rad EJ, Mohabir PK. Cystic fibrosis and COVID-19: care considerations. Respir Med Case Rep. 2020;31:101226. https://doi.org/10.1016/j. rmcr.2020.101226.

22. Patek P, Corcoran J, Adams L, Khandhar P. SARS-CoV-2 infection in a 2-week-old male with neutropenia. Clin Pediatr (Phila). 2020;59(910):918-20. https://doi.org/10.1177/0009922820920014.

23. Rajdev K, Victor N, Buckholtz ES, et al. A case of Guillain-Barré syndrome associated with COVID-19. J Investig Med High Impact Case Rep. 2020;8:2324709620961198. https://doi.org/10.1177/2324709620961198.

24. Rajdev K, Farr LA, Saeed MA, Hooten R, Baus J, Boer B. A case of extracorporeal membrane oxygenation as a salvage therapy for COVID-19-associated severe acute respiratory distress syndrome: mounting evidence. J Investig Med High Impact Case Rep. 2020;8:2324709620957778. https:// doi.org/10.1177/2324709620957778.

25. Randall M, Minahan T, Mesisca M, Gnass S. Nosocomial methicillinresistant Staphylococcus aureus bacteremia in incarcerated patients with severe COVID-19 infection. Am J Infect Control. 2020;48(12):1568-9. https://doi.org/10.1016/j.ajic.2020.09.005.

26. Bagnato S, Boccagni C, Marino G, Prestandrea C, D'Agostino T, Rubino F. Critical illness myopathy after COVID-19. Int J Infect Dis. 2020;99:276-8. https://doi.org/10.1016/j.ijid.2020.07.072

27. Filocamo G, Mangioni D, Tagliabue $P$, et al. Use of anakinra in severe COVID-19: a case report. Int J Infect Dis. 2020;96:607-9. https://doi.org/10. 1016/j.ijid.2020.05.026.

28. Posteraro B, Torelli R, Vella A, et al. Pan-echinocandin-resistant Candida glabrata bloodstream infection complicating COVID-19: a fatal case report. J Fungi (Basel). 2020. https://doi.org/10.3390/jof6030163.

29. Regazzoni V, Loffi M, Garini A, Danzi GB. Glucocorticoid-induced bacterial endocarditis in COVID-19 Pneumoniaã - something to be concerned about? Circ J. 2020;84(10):1887. https://doi.org/10.1253/circj.CJ-20-0462.

30. Spannella F, Ristori L, Giulietti F, et al. A 95-year-old patient with unexpected coronavirus disease 2019 masked by aspiration pneumonia: a case report. J Med Case Rep. 2020;14(1):82. https://doi.org/10.1186/ s13256-020-02432-7.

31. Posteraro B, Torelli R, Vella A, et al. Pan-echinocandin-resistant Candida glabrata bloodstream infection complicating COVID-19: a fatal case report. J Fungi (Basel). 2020. https://doi.org/10.3390/jof6030163

32. De Pascale G, De Maio F, Carelli S, et al. Staphylococcus aureus ventilatorassociated pneumonia in patients with COVID-19: clinical features and potential inference with lung dysbiosis. Crit Care. 2021;25(1):197. https:// doi.org/10.1186/s13054-021-03623-4.

33. Adachi T, Chong J-M, Nakajima N, et al. Clinicopathologic and immunohistochemical findings from autopsy of patient with COVID-19, Japan. Emerging Infect Dis. 2020. https://doi.org/10.3201/eid2609.201353.

34. Hoshiyama T, Wada T, Nihonyanagi S, et al. Clinical and microbiological features of asymptomatic SARS-CoV-2 infection and mild COVID-19 in seven crewmembers of a cruise ship. Intern Med. 2020;59(24):3135-40. https://doi.org/10.2169/internalmedicine.5601-20.

35. Hamzavi SS, Gholami MA, Sanaei Dashti A. A case of COVID 19 and Staphylococcus coinfection. Arch Iran Med. 2020;23(8):568-9. https://doi. org/10.34172/aim.2020.62.

36. Sharifipour E, Shams S, Esmkhani M, et al. Evaluation of bacterial co-infections of the respiratory tract in COVID-19 patients admitted to ICU. BMC Infect Dis. 2020;20(1):646. doi:https://doi.org/10.1186/ s12879-020-05374-z

37. Chandran S, Avari M, Cherian BP, Suarez C. COVID-19-associated Staphylococcus aureus cavitating pneumonia. BMJ Case Rep. 2021. https://doi.org/ $10.1136 /$ bcr-2021-243726
38. Hussain A, Roberts N, Oo A. Prosthetic aortic valve endocarditis complicated by COVID-19 and hemorrhage. J Card Surg. 2020;35(6):1348-50. https://doi.org/10.1111/jocs.14643.

39. Ramos-Martínez A, Fernández-Cruz A, Domínguez F, et al. Hospitalacquired infective endocarditis during Covid-19 pandemic. Infect Prev Prac. 2020;2(3):100080. https://doi.org/10.1016/j.infpip.2020.100080

40. Valga F, Vega-Diaz N, Monzon T, et al. Role of extended hemodialysis in COVID-19: a case report. Nefrología (English Edition). 2020;40(4):487-489. https://doi.org/10.1016/j.nefroe.2020.05.002

41. ElSeirafi MM, Hasan HM, Sridharan K, Zamoori A, Alkhawaja S, Pasha SAA. Efficacy and safety of tocilizumab in critically ill adults with COVID-19 infection in Bahrain: a report of 5 cases. Respir Med Case Rep. 2020;30:101139. https://doi.org/10.1016/j.rmcr.2020.101139.

42. Chen J, Tian C, Cheng X, Wang R, Zhou H, Zeng X. A case of asymptomatic SARS-CoV-2 infection followed by secondary community acquired pneumonia. Quant Imag Med Surg. 2020;10(11):2208-11. https://doi.org/ 10.21037/qims-20-847.

43. Duployez C, Le Guern R, Tinez C, et al. Panton-valentine leukocidin-secreting Staphylococcus aureus pneumonia complicating COVID-19. Emerg Infect Dis. 2020;26(8):1939-41. https://doi.org/10.3201/eid2608.201413.

44. Edrada EM, Lopez EB, Villarama JB, et al. First COVID-19 infections in the Philippines: a case report. Trop Med Health. 2020;48:21. https://doi.org/ 10.1186/s41182-020-00203-0

45. Son $\mathrm{H}-J$, Kim T, Lee $\mathrm{E}$, et al. Risk factors for isolation of multi-drug resistant organisms in coronavirus disease 2019 pneumonia: a multicenter study. Am J Infect Control. 2021. https://doi.org/10.1016/j.ajic.2021.06.005.

46. Lévesque V, Millaire É, Corsilli D, Rioux-Massé B, Carrier F-M. Severe immune thrombocytopenic purpura in critical COVID-19. Int J Hematol. 2020;112(5):746-750. https://doi.org/10.1007/s12185-020-02931-9

47. Joseph C, Togawa Y, Shindo N. Bacterial and viral infections associated with influenza. Influenza Other Resp Virus. 2013;7(Suppl 2):105-13. https://doi.org/10.1111/irv.12089.

48. Ioannidis JPA. Infection fatality rate of COVID-19 inferred from seroprevalence data. Bull World Health Organ. 2021;99(1):19-33F. https://doi.org/10. 2471/BLT.20.265892.

49. Morris DE, Cleary DW, Clarke SC. Secondary bacterial infections associated with influenza pandemics. Front Microbiol. 2017;8:1041. https://doi. org/10.3389/fmicb.2017.01041.

50. Naimi TS, LeDell KH, Como-Sabetti K, et al. Comparison of communityand health care-associated methicillin-resistant Staphylococcus aureus infection. JAMA. 2003;290(22):2976-84. https://doi.org/10.1001/jama.290. 22.2976.

51. Klein NC, Go CH, Cunha BA. Infections associated with steroid use. Infect Dis Clin North Am. 2001;15(2):423-32. https://doi.org/10.1016/s08915520(05)70154-9

52. Monegro AF, Muppidi $\vee$, Regunath H. Hospital acquired infections. StatPearls. Treasure Island (FL): StatPearls Publishing; 2021.

53. Metersky ML, Masterton RG, Lode H, File TM, BabinchakT. Epidemiology, microbiology, and treatment considerations for bacterial pneumonia complicating influenza. Int J Infect Dis. 2012;16(5):e321-31. https://doi. org/10.1016/j.jijid.2012.01.003

54. Redi D, Raffaelli CS, Rossetti B, De Luca A, Montagnani F. Staphylococcus aureus vaccine preclinical and clinical development: current state of the art. N Microbiol. 2018;41(3):208-13.

55. Klausberger M, Leneva IA, Egorov $A$, et al. Off-target effects of an insect cell-expressed influenza HA-pseudotyped Gag-VLP preparation in limiting postinfluenza Staphylococcus aureus infections. Vaccine. 2020;38(4):859-67. https://doi.org/10.1016/j.vaccine.2019.10.083.

\section{Publisher's Note}

Springer Nature remains neutral with regard to jurisdictional claims in published maps and institutional affiliations. 